\title{
Programa educacional público paulista Inova Educação: transformação hoje, inspiração amanhã.
}

\section{São Paulo public educational program Inova Educação: transformation today, inspiration tomorrow}

\author{
Rodrigo Pereira da Silva ${ }^{1}$
}

\section{RESUMO}

Este trabalho envolve a mudança na educação pública paulista a partir do Programa Inova, refletindo a respeito do impacto das ações administrativas na prática docente. $\mathrm{O}$ desenvolvimento do texto foi feito através da análise documental e bibliográfica. O programa resultou em alterações na rotina, novas matérias e imputou mais responsabilidade para alunos e professores. Logo, a escola está incorporando metodologias de controle de gestão e fazendo com que as ações de professores e alunos busquem metas estabelecidas que são representadas na nota no Índice de Desenvolvimento da Educação Brasileira (IDEB).

Palavras-chave: Educação; Inova; Professor; Trabalho docente; Escola.

\section{ABSTRACT}

This final work involves the change in public education in São Paulo based on the Inova Program, reflecting on the impact of administrative actions on teaching practice. The development of the text was done through documental and bibliographic. The program resulted in changes in routine, new subjects and more responsibility for students and teachers. Therefore, the school is incorporating management control methodologies and making the actions of teachers and students seek established goals that are represented in the score in the Brazilian Education Development Index (IDEB).

Keywords: Education; Inova; Teacher; Teaching work; School.

\section{INTRODUÇÃO}

O presente trabalho tem como objeto o Programa Inova Educação: transformação hoje, inspiração amanhã, projeto que está sendo implementado pelo governo estadual paulista nas unidades de ensino da rede pública conta com a cooperação

\footnotetext{
${ }^{1}$ Mestre em Ciências Sociais pelo Programa de Pós-Graduação em Ciências Sociais UNESPAraraquara/SP. E-mail: rodrigounesp@gmail.com; ORCID: https://orcid.org/0000-0003-1653179X
} 
do Instituto Ayrton Senna (IAS). Para a confecção deste texto, foi feita investigação nos sites do Programa Inova e IAS interpretados a luz das contribuições de trabalhos do campo da Ciências Sociais. Compõem a bibliografia Laval (2019) e Freitas (2018) indicando a ação neoliberal na educação pública e implantando formação ligada a prevalência do mercado compartilhado por órgãos internacionais como Banco Mundial (BM), Organização das Nações Unidas para a Educação, a Ciência e a Cultura (UNESCO) e Fundo Monetário Internacional (FMI). Os trabalhos de Depieri (2019), Dagnino (2004), Goulart e Alencar (2021) permitem formação de arcabouçou teórico e crítico a respeito do objeto de pesquisa contribuem com sua pesquisa para compreensão da capilaridade do IAS, seu local de atuação frente ao contexto nacional e internacional. Desta maneira, a pesquisa é qualitativa, conforme "trabalha com o universo de significados, motivos, aspirações, crenças, valores e atitudes, o que corresponde a um espaço mais profundo das relações, dos processos e dos fenômenos que não podem ser reduzidos à operacionalização de variáveis" (Minayo 2002, p. 21-22).

\section{CONTEXTO E ORIGEM}

A educação passa por forte mudança. A compreensão do que ocorre é possível através de olhar investigativo para o passado afim de encontrar as origens das ideias e concepções que norteiam as atuais ações. Fernandes (2019, p. 347) já alertava que "os fenômenos de alteração de padrão estrutural da sociedade custam a se tornar visíveis: quando se percebe o que está acontecendo, a sociedade já não é mais a mesma”. Hoje a construção social imposta pelo Estado através da política educacional está alinhada com preceitos advindos da ordem neoliberal inculcando valores de sociabilidade nos quais o mercado possui primazia. Adalberto Cardoso (2019) em sua obra mostra como que a atuação do Estado brasileiro ao longo da história construiu mercado de trabalho de maneira a ser a utopia buscada pelo trabalhador desde a Era Vargas (1930-1945). A arquitetura do Estado brasileiro com traços prussianos ganhou novas roupagens ao longo da história brasileira e na contemporaneidade permanece atuando promovendo nova utopia. A partir do presente passou a ser introjetada junto da educação conectada com as exigências do capitalismo. No limite, "o que vemos é a história de uma vertente da política de educação integral das fundações e institutos empresariais sendo construída e implementada a partir do Estado (GOUART; ALENCAR, 2021, p. 340)

Através da educação os preceitos neoliberais são introjetados e incorporados pela população. O crescimento de movimentos ligados a educação, com atores ligados a 
burguesia capitalista industrial e financeira ocorre no país paulatinamente desde a redemocratização. De acordo com Dagnino (2004) a reconstrução democrática brasileira ocorrida na década de 1980 possibilitou conjuntura favorável, visibilidade para projeto neoliberal que foi instaurado no país nas décadas seguintes, e teve como oposição nessa querela o projeto democratizante participativo, o qual emergiu a partir das crises dos regimes autoritários e dos diferentes esforços nacionais de aprofundamento democrático. A disputa entre os projetos antagônicos assumiu caráter de disputa de significados ${ }^{2}$ para referências comuns como participação, sociedade civil, cidadania e democracia (DAGNINO, 2004)

O projeto neoliberal foi exitoso. A disputa da sociedade civil foi favorecida pela atuação do campo político que modificou a administração pública, e que de maneira crescente se ausentou da elaboração e execução de políticas públicas abrindo espaço para o chamado terceiro setor. A implementação neoliberal a partir do Presidente Collor (1989) fez surgir a feição do Estado ausente de seu papel garantidor de direitos- através da redução de tamanho e transferência de responsabilidade para a sociedade civil-, constituindo o núcleo do processo global de adequação das sociedades ao modelo neoliberal (DAGNINO, 2004. p. 142).

O movimento empresarial atua cada vez mais na educação em parceria com o Estado, e participa das reformas. A educação é sequestrada "pelo empresariado para atender a seus objetivos de disputa ideológica [...] vista como "serviço" que se adquire, e não como um direito" (FREITAS, 2018, p. 2018). O setor privado através das novas instituições são "novas vozes que não são eleitas, nem supervisionadas pela população, têm tido participação significativa na determinação de políticas educacionais" (AVELAR, 2019, p. 74). O neoliberalismo enxerga a escola a partir de sua ideia de sociedade calcada no livre mercado como força motriz produtora do avanço social com qualidade, refinando a ineficiência por meio da concorrência (FREITAS, 2018, p. 31).

Desde 2007, o movimento empresarial vem definindo as ações do governo Federal para a educação básica, como o Plano de Desenvolvimento da Educação e o Plano Nacional de Educação (20142024) que dispõe sobre toda educação brasileira; apesar das resistências. Os empresários difundem sua agenda e pedagogia principalmente por meio de coalizões como o Todos pela Educação reunindo banqueiros, grandes empresários dos meios de comunicação e

\footnotetext{
${ }^{2}$ Sobre a incorporação de palavras ao grupo neoliberal ver Gentili e Silva (2015)
} 
o chamado "Terceiro Setor" empresarial. (LEHER; VITTORIA; MOTTA; 2017 apud DEPIERI, 2019 p. 4)

Os reformadores empresariais ${ }^{3}$ através das mudanças moldam a formação para finalidade desejada imaginando o futuro da sociedade neoliberal inserido no capitalismo global. A intenção é alcançar o aumento produtivo e o indivíduo passa a ser visto como capital que pode ser transformado, moldado através da educação. A Teoria do Capital Humano $(\mathrm{TCH})$ é que irá nortear o pensamento dos grupos privados que atuam na educação. A TCH está no cerne da doutrina dominante na educação exprimindo a intenção "de mobilizar saberes em número cada vez maior, sob o duplo aspecto de fator de produção e mercadoria" (LAVAL, 2019, p. 51).

A chamada teoria do capital humano $(\mathrm{TCH})$ atribui à educação um lugar estratégico capaz de produzir ganhos adicionais para o capital, desde que a socialização (em sentido durkheimniano) seja bem orientada e o adestramento profissional seja congruente com as demandas do capital. (LEHER apud DEPIERI, 2019 p. 16)

A TCH está atrelada ao "novo espírito do capitalismo" (BOLTANSKI; CHIAPELLO, 2009)

[...] requer um trabalhador que coloque em jogo suas capacidades criativas, suas competências sempre renovadas e atualizadas, que invista permanentemente no crescimento de seu "capital humano", no seu "saber-ser", que seja autônomo e capaz de colher as oportunidades que o mercado e sua "rede" de contatos lhe oferecem, que assuma os riscos de suas empreitadas sem esperar que o Estado garanta seus direitos de trabalhador. (DE TOMMASI; SILVA, 2020, p. 199)

Neste contexto político é que o IAS está inserido e atua de maneira cooperativa com a Seduc. As premissas comungam com as descritas por Laval (2019) e Freitas (2018), e como veremos a seguir o Inova segue a lógica neoliberal em sua concepção, propõe a introjetar valores e a construção de projeto de vida atrelados a sociabilidade capitalista liberal advindas do Estado para a população estudantil.

\footnotetext{
${ }^{3} \mathrm{O}$ termo tem origem no conceito reforma empresarial que Freitas (2018) faz uso e que foi proposto por Ravitch (2013) que define seu significado: “Reforma' realmente não é um bom nome, porque os defensores dessa causa não procuram reformar a educação pública, mas transformá-la em um setor empreendedor da economia... as raízes desse movimento de reforma podem ser atribuídas a uma ideologia radical que tem uma desconfiança fundamental em relação à educação pública e uma hostilidade ao setor público em geral. O movimento de 'reforma' é na verdade um movimento de 'reforma empresarial', financiado em grande parte por fundações, gerentes de fundo hedge de Wall Street, empreendedores e o Departamento de Educação dos EUA. O movimento está determinado a cortar os custos e maximizar a concorrência entre escolas e entre professores. (RAVITCH, 2013 apud FREITAS, 2018, p. 39)
} 


\section{INOVA EDUCAÇÃO E OBSERVAÇÕES}

O ano de 2020 iniciou com uma expectativa alta no estado de São Paulo. O motivo era a implementação do Inova Educação: transformação hoje, inspiração amanhã. Os preparativos se iniciaram no ano anterior. A Secretaria da Educação de São Paulo formou parceria junto ao IAS e, seguindo seus dizeres, "baseados em experiências exitosas" (LANÇAMENTO DO PROGRAMA INOVA EDUCAÇÃO, 2019)

“... a parceria cujo produto é o Programa Inova Educação teve início com o Acordo de Cooperação entre a Seduc e o IAS (SÃO PAULO, 2018), em 5 de abril de 2018 com validade até 31 de dezembro de 2020, voltado para a pactuação de um instrumento que construísse "uma política de educação integral na rede pública estadual paulista" (SÃO PAULO, 2018, p. 13). Neste instrumento legal, cada parceiro assume os custos de suas ações, sem transferência de valores monetários entre ambos. Os eixos da parceria são as ações voltadas à construção de uma visão comum sobre Educação Integral, baseada nas "competências para o século XXI", de uma matriz de referência, de estratégias de organização do currículo, formação, acompanhamento, avaliação e à implementação por meio do projeto piloto e à institucionalização, com a expansão do modelo para toda a rede." (GOULART; ALENCAR, 2021, p. 339)

O Inova apresenta-se como correção de rumos da educação, mas da impressão de estar alinha com o que Freitas (2018) e Laval ${ }^{4}$ (2019) argumentam como sendo alinhamento a diretrizes de organismos internacionais.

[...] a reforma permite o alinhamento da escola à necessidade dos novos processos produtivos, coordenado pela OCDE e agências internacionais, visando a inserção das cadeias produtivas nacionais na lógica das cadeias internacionais, o que exige um alinhamento com as necessidades da Revolução Industrial 4.0 e as reformas que ela demanda. (FREITAS, 2018, p. 29)

As mudanças propostas caminham no sentido de adequação da formação pública ofertada. Segundo Fernandes (2020) quando a burguesia não consegue realizar seus

\footnotetext{
${ }^{4}$ Sobre o tema Laval (2018, p. 19) diz que "a concepção de educação que inspira as reformas [...] não é fruto de uma espécie de complô, mas de uma construção muito eficaz, na medida em que não é possível identificar facilmente uma ou várias instâncias responsáveis por ela, o processo é difuso, tem múltiplas plataformas nacionais e internacionais cuja ligação não é clara à primeira vista, utiliza em geral vias técnicas e se apresenta com frequência com as melhores intenções "éticas". As organizações internacionais (Organização Mundial do Comércio - MOC, Organização para Cooperação e Desenvolvimento Econômico- OCDE, Banco Mundial, Fundo Monetário Internacional - FMI, Comissão Europeia) contribuem para essa construção, transformando "constatações", "avaliações" e "comparações" em oportunidades para produzir um discurso global que tira sua força justamente da dimensão planetária."
} 
planos no âmbito privado, ela faz uso do Estado e de sua força coercitiva para exercer sua vontade pessoal.

O objetivo, segundo as diretrizes do programa, é tornar a escola mais conectada com os anseios dos estudantes e formá-los para as competências do século 21. Essas competências contemplam um variado conjunto de habilidades, conhecimento e atitudes e, de acordo com o comunicado à imprensa postado no site do programa "[...] estão relacionadas ao sucesso na vida e a uma inserção mais qualificada em um mercado de trabalho, o qual está em constante mudança em função das transformações tecnológicas" (INOVA, 2019, p. 22). Além disso, o Inova objetiva realocar o discente em posição centralizada no processo de aprendizagem, possibilitando protagonismo e engajamento. O objetivo está alinhado com o desejo dos reformadores empresariais

Do ponto de vista das finalidades da educação, embora nem sempre explicitas, os reformadores visam a implementação de reformas educacionais para, por um lado, garantir o domínio de competências e habilidades básicas necessárias para a atividade econômica revolucionada pelas novas tecnologias e processos de trabalho (Revolução 4.0) e, por outro, garantir que tal iniciativa se contenha dentro da sua visão de mundo que se traduz em um status quo modernizado. O objetivo final deste movimento é a retirada da educação do âmbito do "direito social" e sua inserção como "serviço" no interior do livre mercado, coerentemente com sua concepção de sociedade e de Estado. (FREITAS, 2018, p. 41-42)

O programa coloca na posição de protagonismo a escola e as famílias no processo de desenvolvimento de competências socioemocionais. As competências, de acordo com o programa, ajudam na melhoria da aprendizagem dos estudantes e são de grande importância para "estudantes que vivem em situação de vulnerabilidade e, portanto, têm menos oportunidades" (INOVA EDUCAÇÃO, 2019, p. 2). A resultante do processo demonstrado no documento é a melhora de aprendizado e facilitação da aprendizagem das habilidades cognitivas. O desenvolvimento socioemocional gerará impacto em futuras realizações da vida do estudante e assim será multiplicador benéfico para a sociedade. Através de olhar crítico proporcionado por Goulart e Alencar (2021) o que norteia o Inova é a ideia de

[...] "escola para a vida" [...] subordinando a escola às demandas de conhecimentos voltados à resolução de problemas que exige um jovem criativo e "antenado" ao uso de tecnologias, cujo protagonismo voltase para um engajamento de tipo empreendedor. A avaliação dos componentes do Programa Inova Educação, são assim denominados: engajamento total, satisfatório ou parcial, em que o docente pondera se o estudante "comprometeu-se de forma produtiva e efetiva nas ações e atividades desenvolvidas. (GOULART; ALENCAR, 2021, p. 351) 
As alterações apresentadas implicaram uma mudança na carga horária; a duração das aulas, que era de 50 minutos, passou para 45 minutos, e o número de aulas passou de seis para sete por dia. Além disso, houve a criação de três novas matérias: Projeto de Vida (PV), Eletivas e Tecnologias. A consequência direta e que mais chamou a atenção dos alunos foi que a saída da escola ocorreria 15 minutos mais tarde do que era habitual. Assim o tempo de permanência na escola passou de 5 horas para 5 horas e 15 minutos por dia.

A mudança apresentada devido ao programa mostrou, logo de início, vários desafios. Quem seriam os docentes responsáveis pelas novas disciplinas? Como a escola se adaptaria à nova organização escolar?

\section{CONTEXTO DE MUDANÇA}

A educação estadual deveria se adequar às mudanças feitas na instância federal. Assim, a primeira alteração diz respeito à organização escolar de nossa nação. $\mathrm{O}$ Ministério da Educação, ainda na gestão Michel Temer, havia aprovado a Medida Provisória 746 de 22 de setembro de 2016 da Reforma do Ensino Médio, além de homologar a nova Base Nacional Comum Curricular (BNCC) ${ }^{5}$. Assim, todos os estados deveriam adequar seus currículos educacionais e o Inova faz parte desse processo, assim como o NOVOTEC 6 que, anterior ao primeiro, também surge nesse contexto.

O sistema educacional paulista é denso e conta com mais de 3,6 milhões ${ }^{7}$ de estudantes, de acordo com o censo escolar de 2013. O número representa $36 \%$ do total de estudantes matriculados no país. O quadro de professores é composto por cerca de 250 mil docentes, porém o número é insuficiente e a falta de professores é uma realidade enfrentada diariamente pela rede. Ainda há a questão das salas de Ensino Fundamental II, que chegam a ter em média 35 alunos, e o Ensino Médio com número ainda superior a esse.

\footnotetext{
${ }^{5}$ Sobre os reformadores empresariais e a BNCC ver Costola; Borghi (2018).

${ }^{6} \mathrm{O}$ programa Novotec oferece cursos técnicos e profissionalizantes gratuitas aos estudantes do ensino médio das escolas estaduais paulistas.

${ }^{7}$ O número atual de estudantes é de mais de 4 milhões. Fonte: Secretaria Estadual de Educação de São Paulo.
} 
A preparação para o ano de 2020 exigiu que os docentes fossem qualificados para as novas disciplinas. A capacitação foi então ofertada através da Escola de Formação dos Profissionais de Educação na modalidade EAD por meio de três cursos iniciais e, posteriormente, mais três cursos de aprofundamento com carga horária de 30 horas cada um, totalizando 180 horas. Entretanto, isso não representou a totalidade do corpo docente ou nem mesmo um número mínimo de professores prontos para ocupar as novas matérias na grade curricular.

As inscrições tiveram início no mês de junho e as aulas iniciaram no formato EAD a partir de 16 de junho, com data limite para 30 de agosto, prorrogada até 05 de setembro. Para professores contratados, a necessidade de realizar o curso era ainda maior porque ele ampliava o leque de opções de aulas que poderiam ser atribuídas.

\section{MOTIVOS PARA A MUDANÇA: A SITUAÇÃO DA EDUCAÇÃO}

No início da legislação (2019-2022), os governos estaduais receberam diagnóstico a respeito da educação elaborado pelo IAS e, a partir dele, novas políticas públicas no campo educacional passaram a ser implantadas (DEPIERI, 2019). O diagnóstico do Instituto, que se confunde com o apresentado pela Gestão Dória, prega a necessidade da melhora de resultados no Índice de Desenvolvimento da Educação Brasileira (IDEB), uma vez que São Paulo apresenta resultado inferior à meta estabelecida, como mostra o gráfico do IDEB do Ensino Fundamental Anos Finais.

O IDEB paulista, de acordo com o INEP, no Ensino Fundamental Anos finais foi superior à meta até 2011, quando o resultado foi de 4,3 e estava 0,1 acima da meta estabelecida. Porém, a partir de 2013, os resultados obtidos ficaram abaixo da meta e a diferença foi sendo acentuada a cada biênio. O declínio paulista apresentou 4,8 como resultado, sendo que a meta estabelecida era de 5,3 pontos no IDEB. Embora o gráfico demonstre avanço dos resultados obtidos, ele ocorreu em uma velocidade inferior ao aumento da meta, fazendo com que os números de São Paulo ficassem abaixo e a diferença aumentasse ano a ano.

A situação dos resultados no Ensino Médio mostra similaridade com o ocorrido no Ensino Fundamental. De 2007 até 2011, o IDEB paulista esteve acima da meta e teve ligeira melhora de 0,3 no período, saindo de 3,4 no ano de 2007 e chegando a 3,9 no ano de 2011. Contudo, no ano de 2013 houve um declínio de 0,2 no IDEB de São Paulo enquanto a meta continuou sua trajetória ascendente, sendo que, naquele ano, o número 
imposto era de 3,9. A diferença que iniciou em 0,2 no ano de 2013, com o resultado paulista observado de 3,7 em relação à meta, alcançou o patamar de 0,8 no ano de 2017 com a meta estabelecida em 4,6 e o resultado observado da rede de 3,8 .

O Instituto Nacional de Estudos e Pesquisas Educacionais Anísio Teixeira (INEP) é uma autarquia responsável pelas avaliações e pela compilação de dados. A meta do IDEB surgiu como condutora de políticas públicas ligadas à melhora da educação nacional. A meta é de que em 2022 o IDEB seja igual a 6. As metas intermediárias foram balizadas pelo INEP no âmbito do programa de metas fixadas pelo Compromisso Todos pela Educação do Ministério da Educação, que trata da educação básica. Traçadas as metas intermediárias, cada sistema deveria acompanhá-la para que a desigualdade educacional fosse superada e a meta estabelecida para o ano do bicentenário da independência fosse atingida. O índice leva em consideração a média de avaliações como Prova Brasil (escolas e municípios), Sistema de Avaliação da Educação Básica, SAEB, além de outros dados obtidos a partir do censo escolar. As avaliações em larga escala medem a proficiência dos alunos em português e matemática.

Junto aos anseios governamentais ${ }^{8}$, ainda há os pais que julgam saber o que seria o melhor para seus filhos. Já os professores e alunos estão juntos nesse processo em que a responsabilidade da vida escolar é delegada ao docente, que deve cumprir currículo, cuidar da turma toda e de diversas outras obrigações, sendo que cada um têm suas próprias responsabilidades. Elas, que já são muitas, aumentaram com o Inova. A redução de 5 minutos na duração das aulas exigiu um processo de adaptação, pois os turnos de trabalho passam de forma extremamente veloz e desgastante. Essa redução de tempo das aulas resultou na maior realização de atividades por parte do docente na escola, especialmente porque foi aumentado o número máximo de aulas lecionadas diariamente de 9 para 11 aulas.

A docência é algo que exige reflexão, leitura corporal em sala de aula para compreender a comunicação não verbal dos alunos, já que é dentro da sala de aula o local de verdadeiro domínio de professores. É nela que a "mágica” deve ocorrer nesse processo em que o docente oportuniza o conhecimento científico para o aluno e, na maioria das

\footnotetext{
${ }^{8}$ As intenções governamentais da busca por melhores resultados "consiste em introduzir, em algum grau, os parâmetros de funcionamento de uma empresa no interior do serviço público, criar ferramentas de aferição e certificação de qualidade (externamente à escola), dar visibilidade das avaliações na mídia e condicionar os recursos hoje disponíveis e metas de aumento da qualidade das redes e das escolas." (FREITAS, 2018, p. 34)
} 
vezes, propõe transformar a linguagem para que o aluno a apreenda. O professor é um alquimista que transforma o conhecimento científico em produto acessível para seu público. O sucesso do docente nessa tarefa tende a representar aprendizagem satisfatória pelos discentes. Nesse processo, nos aproximamos da qualidade social da educação, pois consideramos as condições de vida dos discentes e os aspectos valorativos da educação, vendo-a como um direito e não um privilégio, tendo capacidade emancipatória (BERTAGNA; MELLO, 2020).

A realidade da sala de aula está ao alcance de personagens de fora dela. A aula tende a sofrer pressões externas e o trabalho docente é medido sempre ao seu final quando os alunos fazem as provas e avaliações externas de desempenho. São testes e pesquisas que mostram o resultado educacional. Para o governo, é necessária a mudança na educação pelo imperativo da Reforma do Ensino Médio e pelo resultado (não) alcançado em provas como Programa Internacional de Avaliação de Estudantes (PISA), Sistema de Avaliação da Educação Básica (SAEB) e Sistema de Avaliação de Rendimento Escolar do Estado de São Paulo (SARESP). Além dos testes, o governo estadual realizou pesquisas para justificar mudanças.

A Secretaria de Educação, através de pesquisa realizada com os alunos, descobriu que $87 \%$ dos estudantes desejam receber orientações e ajuda para descobrir suas vocações, sonhos e fazer escolhas da vida. Para $91 \%$ dos estudantes que participaram da pesquisa, é importante ou muito importante aprender a usar novas tecnologias ${ }^{9}$. O diagnóstico junto aos professores é de que $94 \%$ acham importante ter projeto de vida na escola e 93\% acham importante a escola ampliar a capacidade dos estudantes de utilizar tecnologias.

A tempestade perfeita para alterações no campo da educação estava formada com a projeção do cenário: estudantes querendo mudanças; professores (aqueles que participaram das pesquisas) dando sentido às alterações; baixo desempenho por parte dos discentes em exames de avaliação. O foco na melhora dos índices é algo que vem sendo buscado anteriormente ao programa Inova Educação. Primeiro foi lançado o programa Gestão em Foco, implantado em 1082 unidades escolares através da utilização do Método

\footnotetext{
${ }^{9}$ A fonte: Nossa escola em (re)construção. (2019)
} 
de Melhoramento de Resultados (MMR) ${ }^{10}$, a fim de que essas unidades conquistassem avanços educacionais, pedagógicos e de gestão.

As mudanças em processo têm como foco central a melhoria dos resultados, que deve ser expressa nos números obtidos nos exames de avaliação. As ações do governo estadual estão consonantes com a organização federal. Além do compasso alinhado, há a busca por resultado colocando na educação uma visão empresarial. O Ministério da Educação, que já havia aprovado a Reforma do Ensino Médio, posteriormente aprovou a BNCC. As novas disciplinas estão de acordo com as competências elencadas pela base nacional. São 10 competências que devem ser desenvolvidas pelos alunos ao longo de todos os anos da educação básica. As competências estão divididas em 1- conhecimento; 2- pensamento científico, crítico e criativo; 3- repertório cultural; 4- comunicação; 5cultura digital; 6- trabalho e projeto de vida; 7- argumentação; 8- autoconhecimento e autocuidado; 9- empatia e cooperação; 10- responsabilidade e cidadania.

As disciplinas, do ponto de vista ideal ou teórico, depositam o protagonismo, mais uma vez, no aluno, e a responsabilidade do processo é calcada no docente.

O Programa Inova Educação revela essa intencionalidade: formar um novo homem, resiliente, flexível, autônomo, decidido e capaz de se reinventar para inserir-se num mundo do trabalho de contratos precários, de informalidade, de extensão de horários e com uso intenso da tecnologia, ainda que esta se apresente como o meio para seu aprisionamento efetivado pelo individualismo como método (LAVAL; 2011 apud GOULART; ALENCAR, 2021, p. 357)

Os jovens possuem uma educação voltada para o empreendedorismo, tornando-os senhores de suas escolhas e concorrendo com os demais companheiros discentes em uma espécie de "darwinismo social" (FREITAS, 2018) demonstrando o pensamento de que

[...] se o mundo é pautado pela concorrência, há que se preparar as crianças para "competir" nele, tal como ele é. Nenhuma perspectiva de humanização ou transformação social é agregada aos processos educativos, daí seu caráter reacionário e conservador. (FREITAS, 2018, p. 28)

A promessa anunciada foi de que as aulas de Projeto de Vida, a primeira disciplina nova, seriam feitas com atividades que apoiam os alunos no planejamento de sua vida na escola e do seu futuro; auxiliam os estudantes a desenvolverem a gestão do próprio tempo,

\footnotetext{
${ }^{10}$ A intenção do programa é melhorar a aprendizado de 1 milhão de estudantes do Ensino Fundamental e Médio com a formulação de planos de trabalho personalizados e monitorados pela própria comunidade escolar. De acordo com informações da Secretaria, o MMR é utilizado desde o planejamento estratégico para o ano letivo e passa por etapas como identificar os desafios, planejar formas de superá-los e implantar soluções elaboradas.
} 
a organização pessoal e o compromisso com a comunidade. No limite, as três matérias têm como finalidade teórica o sentimento de pertencimento do aluno, além de trabalhar com sua perspectiva de futuro e habilidades socioemocionais. São pensadas para que se trabalhe hoje projetando onde quer se chegar, qual é o objetivo. Ela é ministrada por um docente e ocorre duas vezes na semana.

Há um deslocamento de prioridade, com as competências socioemocionais (CSE) no centro do currículo organizadas, sobretudo, no componente Projeto de Vida, com a subordinação das competências cognitivas, deixando de ser o fundamento da escola no capitalismo financeirizado. O sonho que se transforma em Projeto de Vida é organizado por meio de atividades direcionadas ao planejamento, sob supervisão dos docentes, e acompanhada de expressões que remetem à livre escolha do indivíduo, com a sequência do "varal dos sonhos" dos estudantes, para inspirar docentes a ofertar disciplinas que possam ser expostas no "feirão das eletivas", formando um currículo "à la carte". (GOULART; ALENCAR, 2021, p. 343)

A segunda disciplina criada foi a Eletiva, na qual os estudantes têm a possibilidade de escolher, a cada semestre, as aulas que irão cursar a partir do ofertado pela escola. Desta maneira, as Eletivas são criadas a partir de um feedback dos alunos, que são transformados em conteúdos disciplinares. A terceira disciplina foi Tecnologia e Inovação, que traz aulas focadas no aprendizado do uso de tecnologias do século XXI a fim de criar seus próprios projetos. Durante o treinamento para lecionar a disciplina, foi vinculada a informação nos vídeos transmitidos na plataforma da EFAPE que as escolas receberiam kits de robótica e outros suportes para que a disciplina pudesse ser efetivada, mas, até a parada provocada pela pandemia, a situação permanecia em espera.

A função do docente nessas três novas matérias é praticamente a mesma: observar o estudante enquanto ele realiza atividades; analisar os produtos parciais criados em atividades individuais ou em grupo; promover a autoanálise e autoavaliação do estudante; discutir com outros professores sobre comportamentos e produções do estudante. A avaliação dos discentes ocorre a partir do engajamento do aluno, não havendo o parâmetro de nota de zero a dez.

O fato é que as alterações em curso no estado de São Paulo estão em consonância com mudanças ocorridas na organização federal. Elas introduzem uma lógica empresarial que cria exigências para as escolas públicas. Os programas INOVA e Gestão em Foco fazem parte dessa perspectiva empresarial. 
O contexto macro da educação está desenhado com a definição da $\mathrm{BNCC}^{11}$, assim, uma definição do que se deve ensinar para o aluno já está montada para todo o território nacional, havendo espaço para que cada região incorpore traços regionais no cardápio escolar. Uma vez estabelecido o que deve ter como base da educação, torna-se mais fácil medir a eficácia dos envolvidos no processo educacional. O foco é a obtenção de resultados. Logo, a lógica administrativa é posta em prática dentro do ambiente escolar e seu sucesso depende do trabalho desempenhado em sala de aula. O que está por de trás é o pensamento de que se a prática da certo no setor privado, ela terá eficácia no setor público (FREITAS, 2019).

O sucesso e o fracasso serão medidos com base nos resultados ${ }^{12}$ das avaliações de larga escala, que analisam a proficiência em Português e Matemática. Neste processo, ocorre uma homogeneização dos discentes. Embora a propaganda seja de maior atenção à formação do aluno que não possui mais interesse na escola, o olhar destas novas diretrizes educacionais está voltado para a obtenção de resultados. Basicamente, o docente não se preocupa com a aprendizagem ou com a formação de um aluno humanista; a preocupação está somente no alcance de resultados em provas e preparação para que os alunos se saiam bem na avaliação. A tentativa de alcançar o resultado é feita pelo cumprimento do currículo, que se torna a maior meta do docente dentro do atual processo de ensino, não havendo tempo para que as habilidades sejam de fato trabalhadas. O ritmo é único e o professor luta para que o aluno acompanhe a velocidade imposta verticalmente. $\mathrm{O}$ aluno tenta se encaixar nesse processo, mas, na busca por resultados, os envolvidos no interior da sala de aula estão alienados e renegados cada um à sua responsabilidade individual imputada pelo poder público.

\section{CONSIDERAÇÕES FINAIS}

O Programa Inova através da cooperação com o IAS e formação de concepção de educação provoca modificações profundas na educação pública ofertada dentro das unidades de ensino. As modificações representam sobretudo reforma sistemática da

\footnotetext{
11 "A base nacional tem incluído as chamadas habilidades socioemocionais. Amplia-se a padronização para áreas relativas ao desenvolvimento da personalidade dos estudantes, ampliando-se igualmente aos processos de violência cultural". (FREITA, 2018, p. 84)

${ }^{12}$ Nos casos exitosos, há o pagamento de bônus. Vale ressaltar que foram gastos desde 2008 cerca de 4,2 bilhões de reais que, segundo avaliação do próprio governo paulista, não promoveu melhorias no desempenho dos alunos.
} 
educação carregada de padronização curricular que já vem ocorrendo desde 2007 acompanhada de materiais hiper estruturados e diversificadas ações de controle do trabalho pedagógico (GOULART; ALENCAR, 2021).

A estrada pavimentada pelo Programa pode ser associada com o que Cardoso (2019) chamou de "utopia" quando abordava os direitos trabalhistas outorgados pelo Estado Vargas em seu primeiro mandato. Naquele tempo "o Estado capitalista brasileiro construiu uma utopia irresistível num ambiente de grande vulnerabilidade socioeconômica das massas: a utopia da proteção Estatal representada pela legislação social e trabalhista" (CARDOSO, 2019, p. 185). Agora está construindo a utopia do projeto de vida individualizado que deverá ser concretizado no mercado sob única e exclusiva responsabilidade do indivíduo corroborando ainda mais com a relevância de ser empreendedor dentro deste sistema. A retórica empreendedora contamina o agir político dos sujeitos e é apresentado como caminho possível para o êxito econômico (DE TOMMASI; SILVA, 2020).

A nova "utopia" impõe a construção de sujeitos alinhados as exigências e dotados de competências. "Um trabalhador que se ative permanentemente, que corra atrás, que enfrente os desafios, as incertezas, que aprenda com as caídas, que invista na produção de si, em sua imagem de sucesso, em sua capacidade de "resiliência". Que seja empreendedor de si mesmo" (DE TOMMASI; SILVA, 2020, p. 199). A escola, instituição social, possui papel preponderante no processo de socialização de seus discentes e "os indivíduos constroem-se, senão como reflexo, ao menos em estreita relação com as estruturas sociais: valores culturais, normas de conduta, instituições, clivagens sociais, classes, estilos familiares" (MARTUCCELLI; 2005 apud SANTOS, 2018, p. 27).

O docente é dragado para dentro do processo e afogado pelas exigências impostas. O tempo é escasso para reflexão e as demandas vão se avolumando. O trabalho do docente é mais uma vez atacado, forçado a contribuir com um projeto público cravejado de intencionalidades do mercado, marcado pelo movimento proposital do Estado que abre espaço em seu interior para uma instituição conectada aos preceitos do capitalismo financeiro 


\section{REFERÊNCIAS}

AVELAR, Marina. O público, o privado e a despolitização nas políticas educacionais. In: CÁSSIO, Fernando (org.). Educação contra barbárie: por escolas democráticas e pela liberdade de ensinar. São Paulo: Boitempo, 2019.

BERTAGNA, Regiane H.; MELLO, Liliane R. Qualidade e avaliação: influências e significados na educação brasileira. Revista Educação e Políticas em Debate, v. 9, n. 2, p. 287-304, 2020. Disponível em: https://bit.ly/3bDiMYw. Acesso em: 24 jun. 2021.

CARDOSO, Adalberto Moreira, 1961- A Construção da Sociedade do Trabalho no Brasil: Uma investigação sobre a persistência secular das desigualdades. 2 ed. - Rio de Janeiro, Amazon, 2019.

COSTOLA, Andresa; BORGHI, Raquel. Os reformadores empresariais e as políticas educacionais: análise do movimento todos pela base nacional comum. Revista on line de Política e Gestão Educacional, Araraquara, v. 22, n. esp3, p. 1313-1324, 2018. Disponível em: https://periodicos.fclar.unesp.br. Acesso em: 19 jun. 2021.

DAGNINA, Evelin. Construção democrática, neoliberalismo e participação: os dilemas da confluência perversa. Política e Sociedade, Florianópolis, v. 3, n. 5, p. 139164, 2004. Disponível em: https://periodicos.ufsc.br. Acesso em: 22 de jun. 2021.

DE TOMMASI, L.; MORENO DA SILVA, G. EMPREENDEDOR E PRECÁRIO: a carreira "correria" dos trabalhadores da cultura entre sonhos, precariedades e resistências. REVISTA DE CIÊNCIAS SOCIAIS - POLÍTICA \& TRABALHO, [S. l.], v. 1, n. 52, p. 196-211, 2020. DOI: 10.22478/ufpb.1517-5901.2020v1n52.51018. Disponível

https://periodicos.ufpb.br/index.php/politicaetrabalho/article/view/51018. Acesso em: 10 ago. 2021.

DEPIERI, Adriana A. Instituto Ayrton Senna: proximidades e contradições da atuação empresarial na educação pública no Brasil. 2019. 160f. Dissertação (Mestrado em Educação) - Faculdade de Educação, Universidade de São Paulo, São Paulo, 2019.

GENTILI, Pablo; SILVA, Tomaz (orgs). Neoliberalismo, qualidade total e educação. Petrópolis- RJ: Ed. Vozes, 2015.

FERNANDES, Florestan. A revolução burguesa no Brasil: ensaio interpretação sociológica. São Paulo: Editora Contracorrente, 2020.

FREITAS, Luiz C. A Reforma empresarial da educação: nova direita, velhas ideias. São Paulo: Expressão Popular, 2018.

Os reformadores empresariais da educação e a disputa pelo controle do processo pedagógico da escola. Educação e Sociedade, Campinas, v. 35, n. 129, p. 10851114, out./dez. 2014. Disponível em: https://bit.ly/32cHc84. Acesso em: 30 de jun. 2021. 
GOULART, Débora C; ALENCAR, Felipe. Inova educação na rede estadual paulista: programa empresarial para formação do novo trabalhador. Germinal: Marxismo $e$ Educação em Debate, Salvador, v.13, n.1, p.337-366, abr. 2021. Disponível em: https://periodicos.ufba.br/index.php/revistagerminal/article/view/43759/24618. Acesso em: 09 de ago. 2021.

GOVERNO DO ESTADO DE SÃO PAULO. Eletivas. Disponível em: https://bit.ly/3k549Ah. Acesso em: 29 de jun 2021. 2021.

Formação e atribuição. Disponível em: https://bit.ly/3ifQSnJ. Acesso em: 01 jun.

Inova Educação: lançamento 2. Disponível em: https://bit.ly/33iB6T8. Acesso em: 02 jun. 2021.

Inova Educação: Jornalistas. Disponível em: https://bit.ly/2GD2Dqs. Acesso em: 27 de jun. 2021.

Disponível em: https://bit.ly/2ZjZMtd. Acesso em: 28 de jun 2021.

Tecnologia. Disponível em: https://bit.ly/2R9i6Rc. Acesso em: 02 jun. 2021.

INSTITUTO AYRTON SENNA. Instituto Ayrton Senna. Disponível em:

https://institutoayrtonsenna.org.br/ Acesso em: 24 de jun. 2021.

. Desafios para a política educacional- São Paulo. 2018. Disponível em: https://institutoayrtonsenna.org.br Acesso em: 30 de jun. 2021.

Diagnóstica da Educação Básica- Estado de São Paulo. 2018. Disponível em: https://institutoayrtonsenna.org.br Acesso em: 01 de jul. 2021.

LAVAL, Christian. A escola não é uma empresa: o neoliberalismo em ataque ao ensino público. 1 ed. São Paulo; Boitempo, 2019.

Minayo, M C S (2002). Ciência, técnica e arte: o desafio da pesquisa social. In: Minayo, MCS. (Org.). Pesquisa social: teoria, métodos e criatividade. Petrópolis: Vozes.

PIOLLI, Evaldo; SALA, Mauro. O Novotec e a implementação da Reforma do Ensino Médio na rede estadual paulista. Crítica Educativa, Sorocaba, v. 5, n. 1, p. 183-198, jan./jun. 2019. Disponível em: https://bit.ly/2RbkdUu. Acesso em: 24 de jul. 2021.

SECRETARIA DA EDUCAÇÃO. Lançamento do programa Inova Educação.

Disponível em

https://www.youtube.com/watch?v=aFZCaKHVVVM\&list=PL6fldOITrOirJJRYkRaiM d75tGgeChVJd\&ab_channel=SecretariadaEduca\%C3\%A7\%C3\%A3o Acesso em: 03 de jul. 2020.

SANTOS, Raquel Souza dos. E depois da escola? Desafios de jovens egressos do ensino médio público na cidade de São Paulo. 2018. Tese (Doutorado em Educação) - Faculdade 
de Educação, Universidade de São Paulo, São Paulo, 2018. doi:10.11606/T.48.2019.tde15042019-170620. Acesso em: 2021-08-19.

SILVA, Rodrigo Pereira da. Programa Paulista Inova Educação (2020): O mercado adentrando a escola. Brazilian Journal Development, Curitiba, v.7, n.3, p.23348-23367 mar. 2021. Disponível em: https://www.brazilianjournals.com Acesso em: 10 de jul. 2021

Recebido em: 15/12/2021

Aprovado em: 18/01/2022

Publicado em: 20/01/2022 